\title{
A cultura da infância e a formação
}

\section{do professor}

Maria Lucia Medeiros

O texto relata as experiências do projeto "Brincar: o brinquedo e a brincadeira na infância”. Voltada para a formação de professores, gestores escolares e gestores de secretarias de educação, a iniciativa objetiva possibilitar a desconstrução de concepções idealizadas a respeito das crianças, substituindo-as pela percepção destas como sujeitos que possuem maneiras de agir diferentes daquelas dos adultos e que se expressam por meio de diferentes linguagens. A proposta é efetivada a partir do compartilhamento e realização de brincadeiras do repertório infantil e da observação de crianças brincando em diferentes contextos e espaços sociais, práticas que oferecem ao público participante a possibilidade de reflexão a respeito da infância e de suas expressões culturais, em especial sobre a brincadeira, que ocupa papel central na cultura infantil.

Palavras-chave: Projeto Brincar; formação de professores; formação de gestores escolares; formação de gestores de secretarias de educação; brincadeiras; cultura da infância 


\section{The culture of childhood and the}

\section{teacher education}

Maria Lucia Medeiros

The text reports the experiences of project "Brincar: o brinquedo e a brincadeira na infância”. Focused on the education of teachers, school managers and education secretariat managers, the initiative aims at permitting the deconstruction of the conceptions idealized on children, replacing them with the perception of them as individuals that have ways of acting that are different from those of the adults and that express themselves through different languages. The proposal is carried out based on the sharing and realization of plays from child repertoire and the observation of children playing in different contexts and social spaces, practices that offer to the participating audience and possibility of reflection on childhood and its cultural expressions, in particular on plays, which occupies a central space in child culture.

key words: Project Brincar; teacher education; school managers education; education secretariat managers; plays; childhood culture 


\section{A cultura da infância e a formação do professor}

MARIA LUCIA MEdeIRos*

Como lidam os(as) professores(as) com a cultura da infância? Está claro para eles que as crianças têm uma cultura que as identificam? Cultura da infância, culturas da infância, cultura da criança, culturas das crianças? 0 que é isso, afinal?

Sarmento define cultura da infância como

a capacidade das crianças em construírem de forma sistematizada modos de significação do mundo e de ação intencional, que são distintos dos modos adultos de significação e ação ${ }^{1}$.

A cultura infantil é tão antiga quanto a infância, ainda que se discuta sobre o momento em que o conceito de infância surgiu. A cultura infantil é única e ao mesmo tempo múltipla. Ela é situada, produzida e modificada dentro de um contexto histórico e social. Reúne aspectos que são próprios de uma dada cultura, em suas expressões e especificidades locais, e outros que se relacionam com a geração, gênero ou faixa etária.

A cultura de pares permite às crianças apropriar, reinventar e reproduzir o mundo que as rodeia, numa relação de convivência que permite exorcizar medos, construir fantasias e representar cenas do quotidiano, que assim funcionam como terapias para lidar com experiências negativas, ao mesmo tempo em que se estabelecem fronteiras de inclusão e exclusão (de gênero, de subgrupos etários, de status etc.) que estão fortemente implicados nos processos de identificação social².

Fazem parte da cultura da infância as brincadeiras, gestos, palavras, rituais. São diversos elementos que as identificam, por meio dos quais elas se expressam, conhecem o mundo, estabelecem relações, lidam com seus

\footnotetext{
* Maria Lúcia Medeiros é pedagoga, com experiência em Educação Infantil e Ensino Fundamental I; atua também como formadora de gestores.
}

medos, angústias, alegrias, se socializam, aprendem, criam e reinventam o mundo de maneira criativa.

Apesar de as crianças estarem inseridas em uma cultura que lhes é própria, nem sempre observamos um entendimento e um olhar cuidadoso dos adultos sobre ela. Nesse sentido, Mouritsen (1997) constata que

\footnotetext{
as culturas da infância realizam-se frequentemente por oposição e numa atitude de contraponto crítico ao projeto educacional, numa espécie de "divisão de trabalho" entre as culturas societais (adultocentradas) escolarmente transmitidas e as culturas infantis.
}

\section{A idealização da criança}

A partir de preocupações como as expostas, nasceu o Projeto Brincar: o brinquedo e a brincadeira na infância. Sua origem está ligada a indagações em relação ao lugar que a brincadeira infantil - uma das expressões da cultura da infância - vem ocupando dentro das instituições de atendimento à infância.

De um lado, cresce a defesa dos direitos da infância, da brincadeira e de a criança se expressar enquanto tal. De outro, observamos um entendimento ainda pouco claro sobre a natureza da brincadeira e, consequentemente, da infância.

Será que brincar é a mesma coisa que realizar atividades lúdicas, recreativas, com objetivos puramente didáticos? Como sensibilizar e subsidiar os professores para olharem para aquilo que é próprio da infância? Como trazer para dentro da escola a cultura da infância?

Essas questões fazem parte do foco central do Projeto Brincar, que, desde 2005, vem realizando formação de educadores(as) - professores (as), gestores(as) de escolas e gestores(as) de secretarias de educação - de diferentes municípios do Estado de São Paulo e de Minas Gerais.

Um foco de trabalho é levar o(a) educador(a) a olhar para as crianças não como seres idealizados (é muito co- 
mum ouvirmos: "a infância é um período de vida da pureza, da inocência"), mas como seres que têm uma maneira de agir distinta da do adulto, que se expressam por meio de diferentes linguagens (corporal, plástica, musical...) e que estão ávidos por conhecer o mundo.

Para isso, reavivam-se as memórias de infância dos próprios educadores(as). Através delas, o grupo em formação começa a perceber as diferentes formas como cada um viveu a infância, as diferentes maneiras de agir, de sentir, de ser criança, e, dessa maneira, gradativamente, vão se dando conta do quanto a escola ainda guarda a expectativa de encontrar um aluno idealizado, que se "comporte", seja "atento" ou fique "quieto".

Outro foco importante é o compartilhamento e realização de brincadeiras do repertório tradicional, patrimônio cultural da infância e, portanto, da sociedade em geral: brincadeiras cantadas, de roda, de "mão", brincadeiras com bola, pega-pega, brincadeiras da tradição oral (adivinhas, parlendas, trava-línguas), entre outras.

Os participantes também são incentivados a observarem as crianças que os rodeiam, em outros espaços, para além da escola - nas praças, ruas, parques, no bairro -, e verem como elas brincam hoje. A proposta é que verifiquem como essa cultura de pares acontece em situação de livre interação.

\section{Abrir a escola para a cultura infantil}

\section{Paralelamente a essas vivências, realizam-se estudos}

e reflexões a partir de autores especialistas no assunto e das práticas dos participantes. Muitos têm sido os depoimentos dos educadores, em formação pelo Projeto, valorizando a importância de relembrarem suas infâncias, aumentarem seus repertórios de brincadeiras e refletirem sobre 0 assunto.

O mais importante pra mim foi resgatar o passado (criança) e vivenciar quais são as sensações, sons e sentimentos que transmitimos às crianças.

Gisele M. Miranda - Sertãozinho, 2009.

A escola não domina o brincar; por isso tem tanta dificuldade de incorporá-lo no seu cotidiano.

Rose - Jundiaí, 2009.

Como em todos os encontros, o elemento marcante é a simplicidade. E é assim que vejo a Educação Infantil, pois é através de elementos simples que ela acontece.

Terezinha Ribeiro - Lorena, 2009.
Vários aspectos vêm mudando na minha prática, mas acredito que os mais importantes foram o fato de eu estar me esforçando para dedicar mais tempo às brincadeiras e o fato de eu ser mais tolerante com brincadeiras cujo tema é a violência, pois passei a entender que se a criança as realiza é porque tem necessidade de fazê-lo.

Ana Paula Magdalena - São Carlos, 2008.

Para mim, o que mais me motivou foi o resgate das brincadeiras do tempo de criança, pesquisar junto aos pais e avós, lembrar momentos preciosos que pude vivenciar com as crianças.

Elisangela - São Carlos, 2008.

Não é só simplesmente brincar e pronto! Você planeja a brincadeira, mas não sabe até onde ela vai chegar - ela vai além. Comecei a brincar com o que a criança traz, não só com o que o Projeto propõe. Todo mundo aprende, todo mundo ensina.

Adriana, Lorena, 2009.

Cada educador/participante valoriza um aspecto diferente abordado nas formações: as suas lembranças de infância através de brincadeiras ou sensações; a ampliação do repertório de brincadeiras da tradição infantil; novas maneiras de olhar para os temas presentes no brincar, nas palavras e nos gestos infantis; a importância de permitir um contato mais próximo com a natureza, entre outros.

Para cada um valeria um vasto comentário. 0 que se liga a todos e é importante refletirmos é a importância de abrirmos mais e mais as portas da escola para essa cultura infantil, tão rica de possibilidades, imaginação, criação, sabedoria e encantamento.

Notas

1 SARMENTO, M. 2009

2 SARMENTO, M. 2009.

3 SARMENTO, M. 2009.

Referências

KRAMER, S. \& LEITE, M.I. Infância: fios e desafios. Campinas, SP: Papirus, 1996. HORTÉLIO, L. “É preciso brincar para afirmar a vida”. Disponivel em: $h t t p: / / w w w$. almanaquebrasil.com.br/podcast/papo-cabeca-com-lydia-hortelio/; acesso: 23 de fevereiro de 2010, 18:05.

MOURITSEN, F. Cultura infantil - cultura lúdica. In: Childhood and Children's Culture. University of Southern Denmark (tradução adaptada de Adriana Friedmann), 2009.

SARMENTO, M. As culturas da infância na encruzilhada da $2^{\underline{a}}$ modernidade. Disponivel em: http://cedic.iec.uminho.pt/Textos_de_Trabalho/textos/ encruzilhadas.pdf; acesso: 23 de fevereiro de 2010, 18:10.

SARMENTO, M. Imaginário e culturas da infância. Disponivel em: http://www. cce.udesc.br; acesso em 7 de outubro de 2009.

SIROTA, R. Emergência de uma sociologia da infância: evolução do objeto e do olhar. In: Revista Éducation et Societés, n. 2, p. 9-33. 1998.

\section{Sites}

http://www1.folha.uol.com.br/folha/treinamento/mapadobrincar http://www.casaredondacentrodeestudos.com.br 


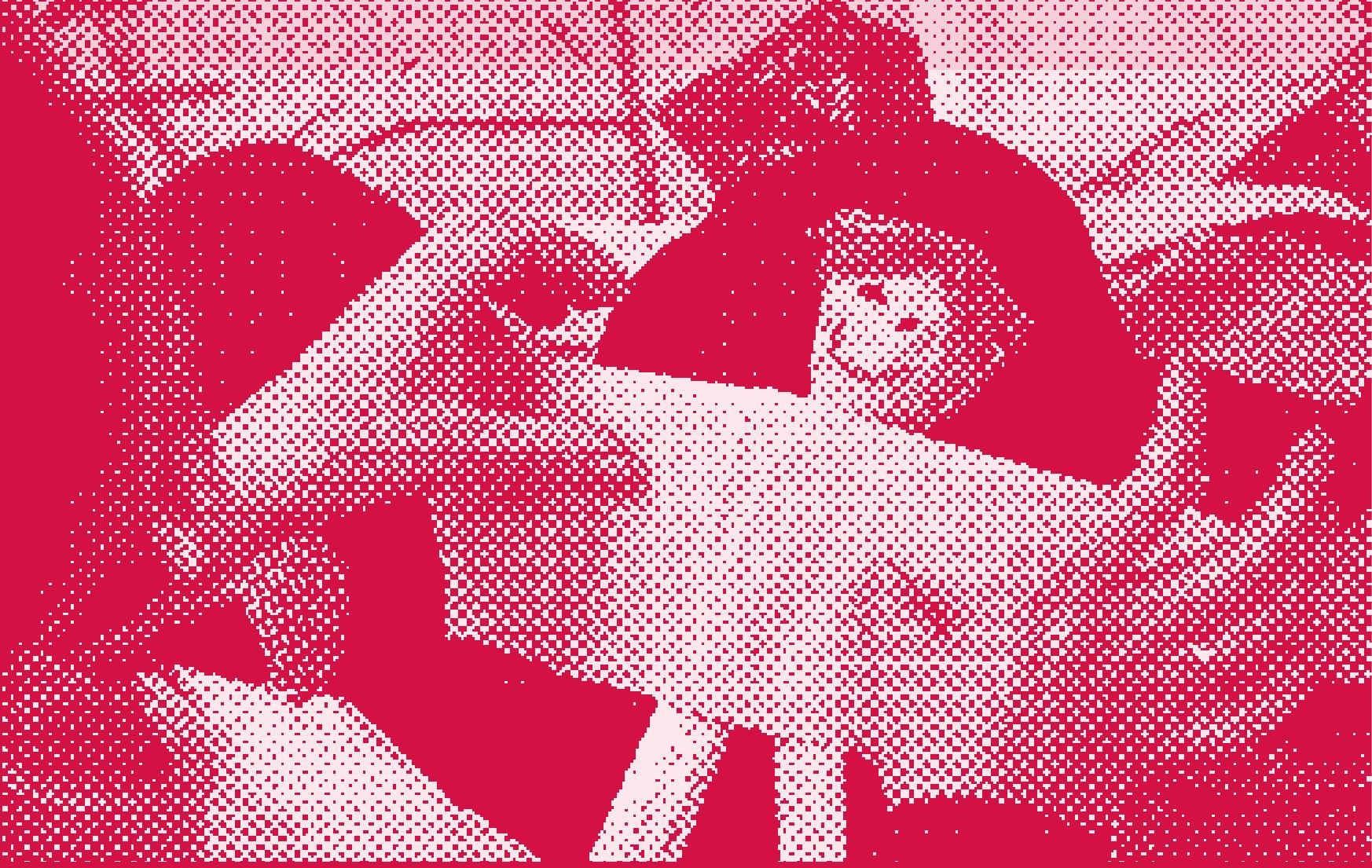

\section{Projeto Brincar}

\section{O Projeto Brincar integra o Programa Território Escola,} iniciativa da Fundação Wolkswagen com coordenação técnica do Cenpec, e se constitui em uma proposta de formação de educadores para que aprimorem suas práticas com relação ao desenvolvimento de atividade recreativas, lúdicas e expressivas com as crianças.

Seu objetivo é formar profissionais e voluntários que trabalham com crianças para que reconheçam o brincar como direito da criança, ampliem conhecimentos sobre o brincar e aprimorem sua prática em relação à brincadeira infantil.

O programa de formação tem duração de dois anos e consiste na realização de sete oficinas no primeiro ano e cinco no segundo ano, com oito horas de duração cada, perfazendo um total de 96 horas, distribuídas em intervalos regulares ao longo dos dois anos letivos.

0 repertório de brincadeiras, o faz-de-conta, os valores que emergem e são construídos no brincar, a interação adulto-criança e criança-criança, o acervo de brinquedos, o uso do tempo e do espaço na unidade de educação infantil, a valorização de diferentes espaços de brincar, a articulação da unidade educacional com outros espaços e instituições da comunidade são conteúdos da formação.

Vivências de brincadeiras, relatos, registros orais e escritos, estudo de textos e discussões de práticas são realizados durante as oficinas, estabelecendo-se relações com as teorias e buscando-se soluções conjuntas e propostas de encaminhamentos para as questões que os educadores trazem.

A formação é oferecida em duas modalidades:

formação de educadores que atuam direto com crianças em creches, EMEls, escola de ensino fundamental e outras instituições que trabalham com crianças; formação de gestores de secretarias de educação para que disseminem o projeto no município formando outros educadores.

Os educadores que atuam diretamente em instituições de educação infantil têm o compromisso de elaborar e desenvolver um plano de ação que tenha por objetivo transformar um ou mais aspectos relacionados ao brincar em sua unidade de trabalho. Os coordenadores pedagógicos, quando integram o grupo, têm o compromisso de socializar o projeto na unidade educacional, envolvendo o maior número possível de educadores.

A formação de gestores tem sido um marco do projeto, pois possibilita irradiar para um número cada vez maior de educadores uma cultura de valorização do brincar. Os participantes vêm para a formação no Cenpec com o compromisso de formar os educadores de sua rede de ensino e de envolver a comunidade conscientizando professores e familiares sobre a importância da brincadeira para a criança. 


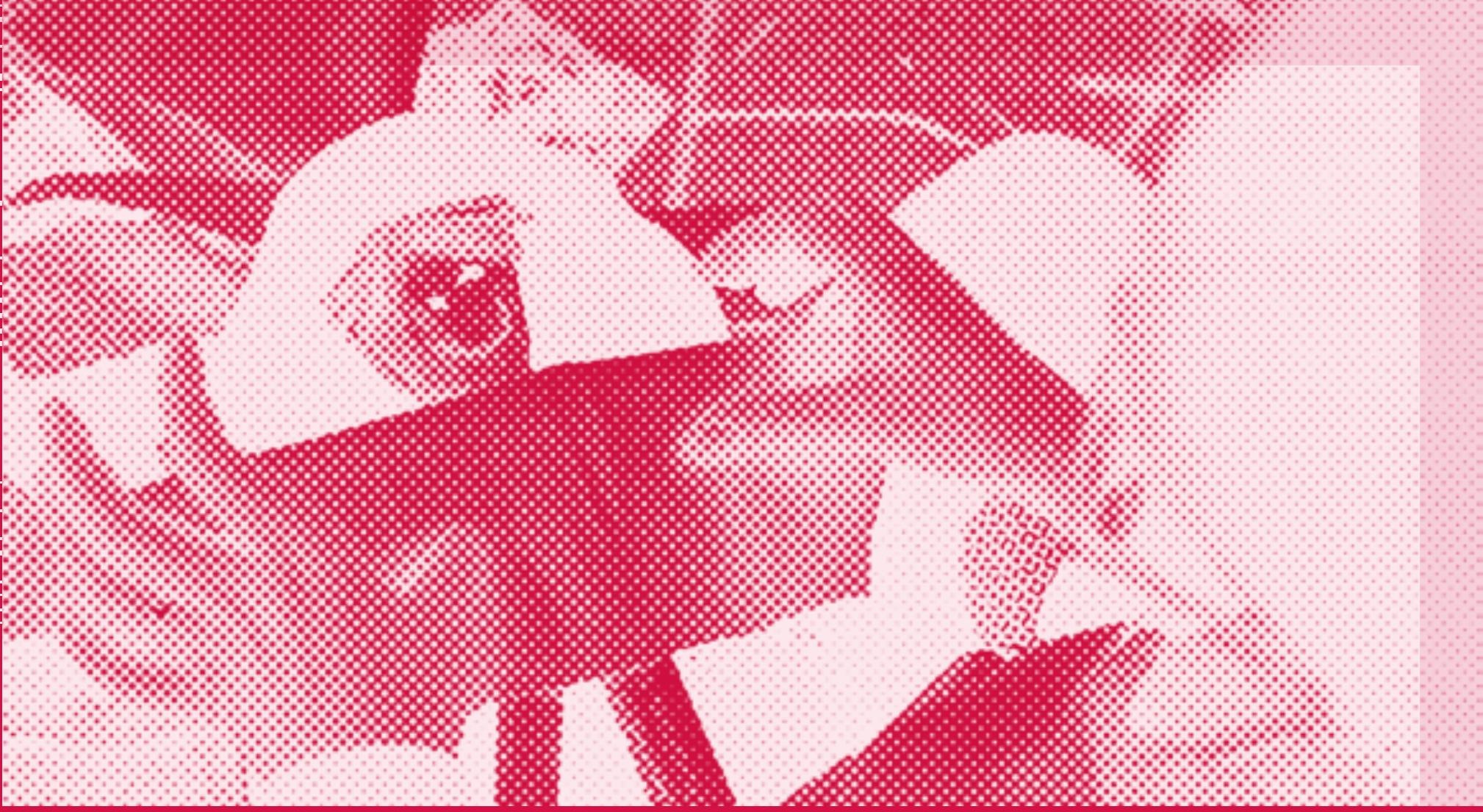

PROFESSORES EM FORMAÇÃO DO PROJETO BRINCAR - ACERVO DO PROJETO BRINCAR

Além das oficinas de formação são realizadas visitas a municípios e unidades educacionais e coletados dados por meio de instrumentos escritos, tendo em vista o acompanhamento e avaliação do projeto.

\section{Histórico}

\section{Cenpec já havia realizado, em 1989, um projeto cen-} trado no brincar que teve como produto o livro Memória e Brincadeiras na Cidade de São Paulo nas Primeiras Décadas do Século XX.

Em 2005, por meio de parceria estabelecida entre a Fundação Volkswagen, o Cenpec e a Secretaria Municipal de Educação de São Paulo, o Projeto Brincar foi realizado nas unidades municipais de educação infantil, abrangendo auxiliares de desenvolvimento infantil, professores de desenvolvimento infantil, professores titulares e adjuntos de educação infantil, coordenadores pedagógicos, supervisores escolares e auxiliares técnicos de educação.

Em 2006 o projeto foi desenvolvido com 31 creches conveniadas com a Prefeitura de São Bernardo do Campo e com representantes de outros 21 municípios do Estado de São Paulo. 0 projeto passou por uma reformulação de objetivos e conteúdos tendo em vista maior integração com o Programa Território Escola. Houve tam- bém a escrita da versão preliminar de uma publicação com conteúdos da formação.

Em 2007, o projeto foi ampliado com a entrada de mais 24 municípios, totalizando 45 municípios participantes. A carga horária da formação também foi ampliada, passou a ter dois anos, totalizando 12 encontros de oito horas e sete visitas de acompanhamento às instituições participantes. Desse modo o projeto passou a ter quatro turmas de formação: duas em continuidade e duas iniciantes. Neste ano foi elaborado um DVD com o repertório de brincadeiras e outros conteúdos do projeto para ser utilizado como apoio aos educadores em seu trabalho na unidade educacional ou como multiplicador do projeto.

Em 2008, deu-se continuidade às formações das turmas que iniciaram em 2007. Desse modo o projeto foi novamente reduzido a duas turmas de formação - uma in loco (diretamente com professores de educação infantil) e outra "por representação" (com representantes de municípios que trabalhavam como multiplicadores do projeto).

Fonte: 〈http://www.cenpec.org.br/memoria/index.php?mod=projetos. view\&id=178> Acesso: 23.novembro.2009, 20:29 